\title{
The incidence and perinatal outcomes of singleton vaginal breech deliveries in a low-resource setting, mpilo central hospital, Bulawayo, Zimbabwe
}

\begin{abstract}
Background: Vaginal breech deliveries are becoming less and less in obstetric units since the publication of the Term Breech Trial in 2000. There are less and less training opportunities for trainees in the specialty. Simulation training could never be as good as having real experience of vaginal breech deliveries. Consequently, many clinicians are now less confident in dealing with vaginal breech deliveries. The objective of this study was to document the incidence and perinatal outcomes of singleton vaginal breech deliveries in a low-resource setting.
\end{abstract}

Methods: This was a retrospective descriptive study covering the period between 1 January 2017 and 31 December 2017 in a tertiary teaching hospital. A paper data collection sheet was used to collect the information. All singleton babies $>24$ weeks gestation born by vaginal breech delivery at the labour ward were included in the study. The data was then analysed.

Results: The incidence of singleton vaginal breech deliveries $0.66 \%$. Teenage mothers accounted for $10.7 \% .21 .4 \%$ of women were unbooked.

$76.8 \%$ were live deliveries and $23.2 \%$ were stillborn, and there was a statistical difference between the two groups, $\mathrm{P}=0.05$. Of the live births, $51.2 \%$ had 1 minute Apgar score of $<7$. By 5 minute $32.6 \%$ still had Apgars scores $<7.98 .2 \%$ of mothers had no complications post delivery, with only 1 case of $\mathrm{PPH}, \mathrm{P}=0.025$.

Conclusions: The incidence of all singleton vaginal breech deliveries $0.66 \%$ and only $0.05 \%$ for term breech. Of the live births, more than half had low 1 minute Apgar score of $<7$. The vast majority mothers had no complications post-delivery.

Keywords: singleton breech, vaginal breech, delivery, perinatal, outcomes, lowresource, settings, central, hospital
Volume 8 Issue I - 2019

\section{Solwayo Ngwenya}

Department of Obstetrics and Gynecology, Mpilo Central

Hospital, Zimbabwe

Correspondence: Solwayo Ngwenya, Department of Obstetrics and Gynecology, Mpilo Central Hospital, P.O. Box 2096, Vera Road, Mzilikazi , Bulawayo, Matabeleland, Zimbabwe, Tel +2639214965, Email drsolngwe@yahoo.co.uk

Received: December 31, 2018 | Published: January 21, 2019
Abbreviations: ARVs, antiretrovirials; PPH, postpartum haemorrhage; HIV, human immunodeficiency virus; LSCS, lower segment caesarean section; SD, standard deviation

\section{Background}

Mpilo Central Hospital is located in Bulawayo and deliveries 9000 deliveries per year. Bulawayo is the second largest city in Zimbabwe after the capital city Harare, with a population of 653,337 as of the 2012 census. ${ }^{1}$ The unit receives referrals from urban and rural centres. It is located in Matabeleland, $439 \mathrm{~km}$ southwest of Harare, on the way to Victoria Falls. In low-resource settings, women with breech presentations have limited choices regarding elective caesarean delivery and vaginal breech delivery due to lack of resources. Some present unbooked and in advanced labour.

Vaginal breech deliveries are becoming less and less in our obstetric units since the publication of the Term Breech Trial in $2000 .^{2}$ This trial gave information that planned caesarean section is better than planned vaginal birth for the term fetus in breech presentation. Over the last years subsequent evidence has not shown conclusively that that caesarean birth is safer than vaginal birth for a fetus in a breech presentation when certain criteria are met. ${ }^{3}$ The best way to deliver a preterm breech still remains unresolved. There has been erosion of clinical skills and confidence. ${ }^{3,4}$ Simulation-based training could never be the substitute for the real clinical experience. Future clinicians would have less skill and confidence in dealing with vaginal breech deliveries.

In low-resource settings caesarean delivery is not a readily available option to all pregnant women. In two studies in Sub-Saharan countries, there was a strong association between vaginal breech delivery of singleton term pregnancies and maternofetal morbidity, with newborns more likely to suffer from birth asphyxia. ${ }^{5,6}$ In a Saudi Arabian study, there was higher neonatal mortality found in vaginal breech delivery for singleton preterm breech fetus. ${ }^{7}$ Vaginal breech delivery is still a safe option without compromising maternal and neonatal outcome if strict criteria are met before and during labour. ${ }^{8,9}$ If there are other obstetric complications, elective caesarean delivery should be undertaken ${ }^{10}$ and here the perinatal outcome would be better. $^{11}$

\section{Methods}

This was a retrospective descriptive study covering the period between 1 January 2017 and 31 December 2017 in a tertiary teaching hospital. A paper data collection sheet was used to collect the information. All singleton babies $>24$ weeks gestation born by vaginal 
breech delivery at the labour ward were included in the study. The data was then analysed. The SPSS Version 21(IBM Corp., Armonk, NY, USA) statistical tool was used to calculate the mean and standard deviation (SD) figures. Descriptive statistics were used to examine patients' characteristics and the outcomes. Chi-sqaure test was used to calculate P-values. A P-value of $<0.05$ was considered statistically significant.

\section{Results}

There were 8439 live births at the unit the period between 1 January 2017 and 31 December 2017. The total number of singleton vaginal breech deliveries was 56, making the incidence of singleton vaginal breech deliveries $0.66 \%$. The mean age was 30.1 years $(\mathrm{SD} \pm 4.5)$. Tables 1-3 show the results. $21.4 \%$ had no known gestational age. $41.1 \%$ of the patients were of term gestation. $37.5 \%$ were of preterm gestation. Teenage mothers accounted for $10.7 \%$. 26.8\% were aged 26-30 years. Nulliparous women were $21.4 \%$, with only $7.1 \%$ of these being term vaginal breech deliveries. The majority of women were second delivery at $28.6 \%$. Booked and referred mothers constituted the majority at $50 \% .21 .4 \%$ of women were unbooked. The HIV seropositive rate was $26.8 \%, 50 \%$ being seronegative and $23.2 \%$ being of unknown status. $89.3 \%$ of patients had no antenatal complication and $10.7 \%$ had a complication. $76.8 \%$ were live births and $23.2 \%$ were stillbirths, and there was a statistical difference between the two groups, $\mathrm{P}=0.05 .55 .3 \%$ of the babies weighed $>2501 \mathrm{~g}$. Of the live births, $51.2 \%$ had 1 minute Apgar score of $<7$. By 5 minute $32.6 \%$ still had Apgars scores $<7.12$ out of 56 patients were primiparous and only 4 were term vaginal breech deliveries for the entire year out of 8439 live births. The incidence of term vaginal breech deliveries was therefore $0.05 \%$ at this unit. Two babies had 1 minute Apgar scores $<7.98 .2 \%$ of mothers had no complications post delivery, with only 1 case of $\mathrm{PPH}, \mathrm{P}=0.025$.

Table I Maternal demographic details of deliveries at Mpilo Central Hospital

\begin{tabular}{lll}
\hline Characteristic & $\mathbf{N}=\mathbf{5 6}(\%)$ & P value \\
\hline Booking status & \\
Booked >4 ANC visits & $16(28.6 \%)$ & \\
Booked(referral) & $28(50.0 \%)$ & \\
Unbooked & $12(21.4 \%)$ & 0.1 \\
Age(years) & \\
Dec-15 & $0(0 \%)$ \\
$16-19$ & $6(10.7 \%)$ \\
$20-25$ & $13(23.2 \%)$ \\
$26-30$ & $15(26.8 \%)$ \\
$31-35$ & $10(17.9 \%)$ \\
$36-40$ & $11(19.6 \%)$ \\
$41-45$ & $1(1.8 \%)$ \\
$>45$ & $0(0 \%)$ \\
Parity & \\
0 & $12(21.4 \%)$ \\
1 & $15(26.8 \%)$ \\
2 & $16(28.6 \%)$ \\
3 & $9(16.0 \%)$ \\
4 & $2(3.6 \%)$ \\
5 & $2(3.6 \%)$ \\
\hline
\end{tabular}

\begin{tabular}{lll} 
Table Continued.... & \\
\hline Characteristic & $\mathbf{N}=\mathbf{5 6}(\%)$ & P value \\
\hline Gestational age(weeks) & \\
$<28$ & $4(7.1 \%)$ \\
$28^{+1}-33^{+6}$ & $9(16.1 \%)$ \\
$34-36^{+6}$ & $8(14.3 \%)$ \\
$37-40$ & $17(30.4 \%)$ \\
$>40$ & $6(10.7 \%)$ \\
Unknown & $12(21.4 \%)$ \\
\hline
\end{tabular}

Table 2 Maternal complications of deliveries at Mpilo central hospital

\begin{tabular}{|c|c|c|}
\hline Variable & $N=56(\%)$ & $P$ value \\
\hline \multicolumn{3}{|l|}{ HIV status } \\
\hline HIV positive & $15(26.8 \%)$ & \\
\hline HIV negative & $28(50.0 \%)$ & \\
\hline Unknown & $13(23.2 \%)$ & \\
\hline ARV's & 15 & \\
\hline \multicolumn{3}{|c|}{ Antenatal complications None } \\
\hline \multirow[t]{2}{*}{ Present } & $48(89.3 \%)$ & \\
\hline & $6(10.7 \%)$ & \\
\hline \multicolumn{3}{|c|}{ Postnatal complications } \\
\hline \multicolumn{3}{|l|}{ None } \\
\hline \multirow[t]{2}{*}{ Present } & $55(98.2 \%)$ & \\
\hline & $\mathrm{I}(\mathrm{I} .8 \%)$ & 0.025 \\
\hline
\end{tabular}

Table 3 Fetal characteristics of breech deliveries

\begin{tabular}{|c|c|c|}
\hline Variable & N/(\%) & $P$ value \\
\hline \multicolumn{3}{|c|}{ Fetal sex $N=56$} \\
\hline Male & $28(50.0 \%)$ & \\
\hline Female & $28(50.0 \%)$ & \\
\hline \multicolumn{3}{|c|}{ Outcome $N=56$} \\
\hline Live & $43(76.8 \%)$ & 0.05 \\
\hline Stillborn & $13(23.2 \%)$ & \\
\hline \multicolumn{3}{|c|}{ Apgar scores $\mathrm{N}=43$} \\
\hline Iminute $<7$ & $22(51.2 \%)$ & \\
\hline I minute $>7$ & $21(48.8 \%)$ & \\
\hline 5 minute $<7$ & $14(32.6 \%)$ & \\
\hline 5 minute $>7$ & $29(67.4 \%)$ & \\
\hline \multicolumn{3}{|c|}{ Birth weight $\mathrm{N}=56$} \\
\hline $500-1000 \mathrm{~g}$ & $7(12.5 \%)$ & \\
\hline $1001-1500 \mathrm{~g}$ & $8(14.3 \%)$ & \\
\hline $150 \mid-2000 \mathrm{~g}$ & $4(7.2 \%)$ & \\
\hline $200 \mathrm{I}-2500 \mathrm{~g}$ & $6(10.7 \%)$ & \\
\hline $250 \mathrm{I}-3000 \mathrm{~g}$ & $12(21.4 \%)$ & \\
\hline $300 \mathrm{I}-3500 \mathrm{~g}$ & $11(19.6 \%)$ & \\
\hline $350 \mathrm{I}-4000 \mathrm{~g}$ & $6(10.7 \%)$ & \\
\hline$>4000 \mathrm{~g}$ & $2(3.6 \%)$ & \\
\hline
\end{tabular}




\section{Discussion}

This study shows that the singleton vaginal breech deliveries are indeed becoming less. The incidence for this unit was $0.66 \%$ for both term and preterm deliveries. The term vaginal breech incidence was even lower at $0.05 \%$. Of the nulliparous women, only $7.1 \%$ of them were term vaginal breech deliveries. There this unit still follows the Term Breech Trial for elective caesarean section for term breech presentation in primiparous women. This signifies low skills for the clinicians. As a teaching tertiary institution with student midwives, junior doctors and practising clinicians the numbers are clearly not enough to acquire or maintain clinical skills.

Skills for vaginal breech deliveries would remain more and more in aircraft-type simulation drills. The incidence of $17.7 \%$ in one unit as of $2003^{12}$ could be lower by now due to the Term Breech Trial effects. Breech presentations at term can be achieved in $85 \%$ of grandmultiparas. ${ }^{13}$ this group of patients would remain as a source of practical skills. More than a fifth of women were unbooked. This may cause problems in that the staff may be unprepared or those with the skills may not be duty leading to poor perinatal outcomes. The HIV seropositive rate was $26.8 \%$ and $23.2 \%$ being of unknown status. They could potentially result in babies being exposed to HIV infection. The prevalence of HIV infection amongst the obstetric patient in the unit is $16 \%$, the national figure for Zimbabwe is $15 \%$ amongst adults 15 years and above. ${ }^{14}$ the figure for HIV seropositive in vaginal breech deliveries was higher than the unit and national average. There were more live births $(76.8 \%)$ than stillbirths $(23.2 \%)$, and there was a statistical difference between the two groups, $\mathrm{P}=0.05$. The babies were mostly of good weight $>2501 \mathrm{~g}$. $51.2 \%$ had 1 minute Apgar score of $<7$, with $32.6 \%$ still $<7$ at 5 minutes. Therefore the immediate perinatal outcome was sub-optimal. This shows that vaginal breech deliveries are associated with adverse fetal outcomes. ${ }^{1,5,6}$ There were no major maternal complications.

\section{Conclusion}

The incidence of singleton vaginal breech deliveries was very low at $0.66 \%$. The overall perinatal outcome was sub-optimal. There were no maternal complications during the study period.

\section{Acknowledgments}

None.

\section{Conflicts of interest}

The author declares there is no conflicts of interest.

\section{References}

1. Zimdat. Census Report 2012. 2018.

2. Hannah ME, Hannah WJ, Hewson SA, et al. Planned caesarean section versus planned vaginal birth for breech presentation at term: a randomised multicentre trial. Term Breech Trial Collaborative Group. Lancet. 2000;356(9239):1375-1383.

3. Hunter LA. Vaginal breech birth: can we move beyond the Term Breech Trial? J Midwifery Womens Health. 2014;59(3):320-327.

4. Walker S. Breech birth: an unsual normal. Pract Midwife. 2012;15(3):2021.

5. Dohbit JS, Foumane P, Tochie JN, et al. Maternal and neonatal outcomes of vaginal breech delivery for singleton term pregnancies in a carefully selected Cameroonian population: a cohort study. BMJ Open. 2017;7(11):e017198.

6. Hogberg U, Claeson C, Krebs L, et al. Breech delivery at a University Hospital in Tanzania. BMC Pregnancy Childbirth. 2016;16(1):342.

7. Gasim TG. Preterm singleton breech delivery in a teaching hospital of Saudi Arabia: vaginal versus caesarean delivery. J Family Community Med. 2008;15(2):65-70.

8. Habib S, Riaz S, Abbasi N, et al. Vaginal Breech Delivery: Still A Safe Option. J Ayub Med Coll Abbottabad. 2013;25(3-4):38-40.

9. Toivonen E, Palomaki O, Huhtala $\mathrm{H}$, et al. Selective vaginal breech delivery at term-still an option. Acta Obstet Gynecol Scand. 2012;91(10):1177-1183.

10. Nkwabong E, Fomulu JN, Kouam L, et al. Outcome of deliveries in Cameroonian nulliparous women. $J$ Obstet Gynaecol India. 2012;62(5):531-535.

11. Adegbola O, Akindele OM. Outcome of term singleton breech deliveries at a University Teaching Hospital in Lagos, Nigeria. Niger Postgrad Med J. 2009;16(2):154-157.

12. Wongwananuruk $\mathrm{T}$, Borriboonhirunsarn $\mathrm{D}$. Incidence of vaginal breech delivery in singleton in Siriraj Hospital. J Med Assoc Thai. 2005;88(5):582-587.

13. Kumari AS, Grundsell H. Mode of delivery for breech presentation in grandmultiparous women. Int J Gynaecol Obstet. 2004;85(3):234-239.

14. Zimdat. Zimbabwe Demographic Health Survey Report 2010/11. 2018. $470 \mathrm{p}$. 